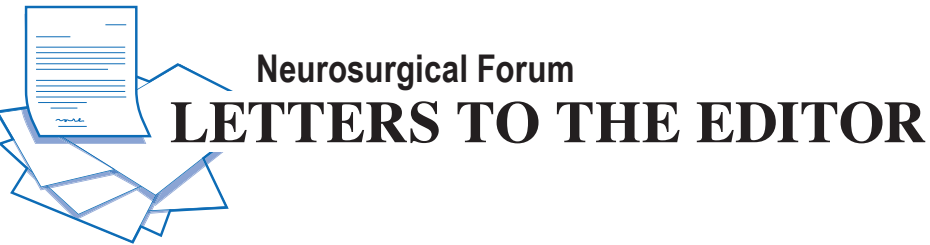

\section{Colloid cysts in children}

TO THE EDITOR: We read with great interest the article by McCrea et al. ${ }^{1}$ (McCrea HJ, Lara-Reyna J, Perera I, et al. Colloid cysts of the third ventricle in children. $J$ Neurosurg Pediatr. 2021;27[6]:700-706) in which they retrospectively reviewed their experience with endoscopic surgery for colloid cysts. In their article, they intended to compare different variables between adults and children. They reported 9 pediatric patients from their own experience and reviewed the literature for pediatric colloid cysts reported thus far. Conspicuously, they missed our study reporting the largest number of pediatric patients operated on for colloid cysts. ${ }^{2}$ We reported 36 patients in our institutional retrospective review from 2003 to $2016^{2}$ and, prior to that, 18 patients in a study reviewing patients from 1998 to 2003. ${ }^{3}$ Though the incidence of colloid cysts in children is low, a review missing the largest series may misguide readers.

There was a male predominance in both of our studies, and the mean ages at presentation in the pediatric age groups were 13 and 14.1 years, which were similar to the age reported by the authors. And while they reported that only 3 patients in their study had symptoms, in our combined experience from two studies, only 1 of 54 patients was asymptomatic. It is very interesting to note that $75 \%$ of our patients had a precipitous presentation like severe headaches, severe vomiting, new-onset diplopia, drop attacks, new-onset blurred vision, or altered sensorium with posturing. In contrast, only 3 of 9 patients in their study had any symptoms. Referral bias may be an important cause of this difference. Seven of our patients required immediate surgery at presentation, and 3 of them underwent placement of an external ventricular drain because of altered sensorium. Importantly, only 1 patient in their study had hydrocephalus, whereas all patients in our study had hydrocephalus.

In the combined institutional experience captured in both of our studies, 17 pediatric patients underwent endoscopic resection, which is the largest experience reported. One of these cases had to be converted to craniotomy because of technical difficulties. All patients in our study had a good outcome despite 2 patients having transient hemiparesis. Note that a review of fatal colloid cysts found that headaches occurred many days before death, and more often the prodrome was longer in the pediatric age group. Inaccurate histories and difficulties in interpreting symptoms in children are points of major concern. As suggested by the authors, because of a cumulative evolution in lesion size over time, along with better surgical outcomes, one should consider operating on colloid cysts in children.

Nishanth Sadashiva, MCh Andiperumal Raj Prabhuraj, MCh

Bhagavatula Indira Devi, MCh

National Institute of Mental Health and Neurosciences, Bangalore, India

\section{References}

1. McCrea HJ, Lara-Reyna J, Perera I, et al. Colloid cysts of the third ventricle in children. $J$ Neurosurg Pediatr. 2021;27(6): 700-706.

2. Vazhayil V, Sadashiva N, Nayak N, Prabhuraj AR, Shukla D, Somanna S. Surgical management of colloid cysts in children: experience at a tertiary care center. Childs Nerv Syst. 2018;34(6):1215-1220.

3. Maqsood AA, Devi IB, Mohanty A, Chandramouli BA, Sastry KV. Third ventricular colloid cysts in children. Pediatr Neurosurg. 2006;42(3):147-150.

4. Lagman C, Rai K, Chung LK, et al. Fatal colloid cysts: a systematic review. World Neurosurg. 2017;107:409-415.

\section{Disclosures}

The authors report no conflict of interest.

\section{Correspondence}

Nishanth Sadashiva: nishanth46@gmail.com; nishanth@ nimhans.ac.in.

INCLUDE WHEN CITING

Published online September 17, 2021; DOI: 10.3171/2021.5.PEDS21267.

\section{Response}

We thank Dr. Sadashiva et al. for their letter regarding our recent publication. We apologize for having neglected to include their most recent publication on the subject. ${ }^{1}$ We agree that it adds important information, as does the earlier work from their group, which we did include. ${ }^{2}$

As they note, our cohort included significantly more asymptomatic pediatric patients than their cohort, which had a significant number of patients presenting with acute deterioration. We noted in our publication that our cohort suggested a more benign presentation in pediatric patients than what had previously been published in the literature. We suspect that referral bias as well as an increasing use of imaging explains the less symptomatic nature of our 
cohort. Had our patients been diagnosed later, it is possible that some may have progressed to becoming symptomatic.

We agree that the excellent surgical results seen across both cohorts, as well as the potential for an increasingly acute and potentially life-threatening presentation if left untreated, argue for considering intervention even in asymptomatic pediatric patients with colloid cyst.

Heather J. McCrea, MD, PhD University of Miami Miller School of Medicine, Miami, FL

Mark M. Souweidane, MD NewYork-Presbyterian Hospital, Weill Cornell Medical College, New York, NY

\section{References}

1. Vazhayil V, Sadashiva N, Nayak N, Prabhuraj AR, Shukla D, Somanna S. Surgical management of colloid cysts in children: experience at a tertiary care center. Childs Nerv Syst. 2018;34(6):1215-1220.

2. Maqsood AA, Devi IB, Mohanty A, Chandramouli BA, Sastry KV. Third ventricular colloid cysts in children. Pediatr Neurosurg. 2006;42(3):147-150.

INCLUDE WHEN CITING

Published online September 17, 2021; DOI: 10.3171/2021.7.PEDS21270.

CAANS 2021, except where prohibited by US copyright law

\section{Standardization of shunt valves: one size does not fit all}

TO THE EDITOR: We read with great interest the article by Berns et al. ${ }^{1}$ (Berns J, Priddy B, Belal A, et al. Standardization of cerebrospinal fluid shunt valves in pediatric hydrocephalus: an analysis of cost, operative time, length of stay, and shunt failure. J Neurosurg Pediatr. 2021;27[4]:400-405). In particular, we regard "standardization" of shunt valves with great concern. As two of the surgeons whose cases are presented in this article, we have particular insight into this project.

The "shunt design trial" that Berns et al. included in their analysis demonstrated that three valves commonly used at that time had similar failure and infection rates. ${ }^{2}$ Data such as these are often incorrectly interpreted as indicating that all shunts function in the same way. Hydrocephalus is a protean condition, and thus a "one-sizefits-all" approach does not apply. Brain compliance and siphoning characteristics vary tremendously from one patient to another. Failure to recognize the nuances of hydrocephalus may have devastating downstream effects. Experienced hydrocephalus surgeons often have acquired equipment preferences through knowledge and experience. More importantly, these surgeons are aware of all available options. While it is true that one valve is not superior to all others in all cases, certain features may be clearly superior in a particular patient with a particular condition. Shunt patients require individualized treatment.

The design of the study reported by Berns et al. ${ }^{1}$ limits the strength of any conclusions. Despite a $62.5 \%$ increase in the percentage of revisions and a $75 \%$ increase in the number of infections in the poststandardization group, the authors report no statistical differences between the groups. Do the cost savings with valve standardization overcome the cost of the increased reoperation rate? The authors cite "gain-sharing" agreements as a rationale for compliance. Strategies such as this should never guide surgical decisions in pediatric patients. Although many advancements in neurosurgery have come from technology, vendor exclusivity stifles innovation opportunities.

Unfortunately, this article exemplifies a disturbing trend in medicine: trivializing the knowledge and training of physicians. The authors cite "stubbornness" as a barrier to compliance. This statement fits a common strategy to blame, minimize, or denigrate physician experience.

Very little in neurosurgery is supported by the elusive "level 1" evidence. Experience brings wisdom and that conveys value. Articles such as this one by Berns et al. ${ }^{1}$ may be incorrectly interpreted by hospital administrators who are not equipped to recognize the scientific limitations of a retrospective paper. Flawed studies may be used as "proof" for decisions that prioritize financial considerations above physician or patient concerns. Furthermore, loss of physician autonomy is an oft-cited cause of "burnout" and job dissatisfaction. ${ }^{3}$ Physician morale is at a critical low in the United States, a situation that is to some extent attributable to unnecessary practice restrictions. The project reported by Berns et al. ${ }^{1}$ was met with resistance from other neurosurgeons at the time, and we had significant concerns regarding limiting the resources we allotted for our highly complex hydrocephalus patients. We remain unconvinced that any perceived cost savings from standardization of shunt valves outweighs the benefits of maintaining viable options. We further place more trust in physician judgment over the use of a simplified checklist in treating complex pediatric neurosurgical patients.

Daniel H. Fulkerson, MD Beacon Children's Hospital, South Bend, IN

Jodi L. Smith, PhD, MD

Goodman Campbell Brain and Spine, Peyton Manning Children's Hospital, Indianapolis, IN

\section{References}

1. Berns J, Priddy B, Belal A, et al. Standardization of cerebrospinal fluid shunt valves in pediatric hydrocephalus: an analysis of cost, operative time, length of stay, and shunt failure. J Neurosurg Pediatr. 2021;27(4):400-405.

2. Drake J, Kestle J, Milner R, et al. Randomized trial of cerebrospinal fluid shunt valve design in pediatric hydrocephalus. Neurosurgery. 1998;43(2):294-303.

3. West C, Dyrbye L, Shanafelt T. Physician burnout: contributors, consequences and solutions. J Intern Med. 2018;283(6):516-529.

\section{Disclosures}

The authors report no conflict of interest.

\section{Correspondence}

Daniel H. Fulkerson: dhfulkerson@beaconhealthsystem.org. 
INCLUDE WHEN CITING

Published online September 17, 2021; DOI: 10.3171/2021.4.PEDS21188.

\section{Response}

We thank Drs. Fulkerson and Smith and appreciate their interest in our study. Physicians should strive to offer safe, timely, and importantly, cost-effective care. Unexplained clinical variance may be at the root of our country's high healthcare costs and suboptimal outcomes compared to the rest of the world. ${ }^{1}$ It is up to all of us as physicians and surgeons to use our clinical and business acumen to lead change and effect improvement on each side of the "iron triangle" of healthcare-access, quality, and cost. ${ }^{2}$

\section{Andrew Jea, MD, MBA, MHA}

The University of Oklahoma College of Medicine, Oklahoma City, OK

\section{References}

1. Tikkanen R, Abrams MK. U.S. Health Care from a Global Perspective, 2019: Higher Spending, Worse Outcomes? CommonwealthFund.org. Published January 30, 2020. Accessed August 2, 2021. https://doi.org/10.26099/7avy-fc29

2. Carroll A. The "Iron Triangle" of Health Care: Access, Cost, and Quality. JAMA Health Forum. Published online October 3, 2012. Accessed August 2, 2021. https://jamanetwork.com/ channels/health-forum/fullarticle/2760240

\section{INCLUDE WHEN CITING}

Published online September 17, 2021; DOI: 10.3171/2021.4.PEDS21205.

CAANS 2021, except where prohibited by US copyright law 